\title{
IUGS: 2008 - 2009 Status Report
}

One year after the election of the present IUGS Executive Committee (EC) is a good opportunity to report on the state of the Union, especially with regard to what was outlined in the Editorial published in the Episodes issue of September 2008.

One of the main ideas for the development of IUGS activities in a context of limited funds was the promotion of national and international "grassroots" actions within the framework provided by the goals, strategies and priorities shared by IUGS and other international organizations. For that purpose a Strategic Planning Committee (SPC) was established to perform a detailed analysis of IUGS external and internal scenarios, with the final goal of addressing as efficiently as possible all Earth science issues relevant to society. Following the approval of the SPC Terms of Reference the two IUGS Vice-Presidents and the Chairs of four IUGS commissions were appointed to provide the necessary links with Adhering and Affiliated organizations in activities related to geoinformation, geoeducation, standards and the environment. Two additional members were appointed for their expertise in relation to International Geological Congresses and strategic matters.

To serve the aims just mentioned, different guidelines were prepared for the work to be done by different members of the EC in relation to Adhering and Affiliated organizations, E-Bulletin, IYPE, IGCP and Inactive Affiliated organizations. At the same time IUGS Adhering and Affiliated organizations and IUGS bodies were contacted and their support was requested, to promote multilateral cooperation among them and to strengthen productive exchange with other international organizations in matters related to IUGS strategic priorities. To facilitate involvement in the international community in all these endeavors, it was proposed and approved by the Council to open Associate membership in IUGS for individual persons - linked to Episodes subscriptions - and for private and public institutions that do not qualify as Adhering and Affiliated organizations but are ready to pay an annual fee.

Supporting the external scenario, a number of actions were taken in order to develop a better interaction with other organizations. Directed to that goal was the IUGS Bureau's participation in the $29^{\text {th }}$ General Assembly of the International Council for Science (ICSU) (October, 2008). On the occasion, a meeting of geo-related organizations under ICSU's umbrella was held to coordinate geoscientific activities. Additionally, in this meeting and in a visit to ICSU's headquarters in February 2009, specific overtures were made to improve the relationship with ICSU's officers and to convey to them the intention to maintain and reinforce IUGS participation in all activities related to ICSU's established priorities on "Environment in Relation to Sustainable Development", "Scientific Data and Information", and "Capacity Building in Science", focused in developing countries. It was thought that IUGS could participate through some of its bodies, such as the IUGS

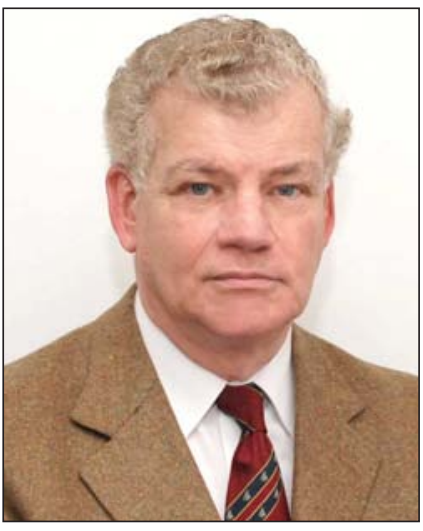
Commission on Education, Training \& Tech Transfer (COGE), the IUGS Commission on Geoscience for Environmental Management (GEM) and the IUGS Commission on the Management \& Application of Geoscience Information (CGI), and in providing links to its Affiliated organizations. On that basis and in order to explore in more detail possible interactions, three members of IUGS Executive Committee were designated to act as liaison between IUGS and ICSU's Regional Offices for Africa, Asia and the Pacific, and Latin America and the Caribbean.

With regard to UNESCO, several meetings were held in February 2009 with different officers of the Natural Sciences Sector and the Division of Ecological and Earth Sciences, as well as with UNESCO's General Director. At those meetings IUGS interests not only in reinforcing existing joint initiatives, such as the International Geoscience Program (IGCP), the Geological Applications of Remote Sensing (GARS) and the International Year of Planet Earth (IYPE 2007-2009), but also in exploring new possibilities in relation to UNESCO's MidTerm Strategy (2008-2013) were discussed. In this context it has been proposed, that IGCP study the implementation of a more accountable emphasis on capacity building and on transference of scientific knowledge from developed to developing countries. As was done for ICSU, three members of the EC were designated to act as liaison between IUGS and UNESCO's Regional Science Offices. Additionally and within a vision focused on geoeducation for the general public, preservation of the environment and geological heritage, sustainable development, transference of knowledge, data management and promotion of global standards, the IUGS has become actively involved in promoting the Geopark initiative as member of the Bureau of the Global Geoparks Network.

Further on the external scenario the IUGS has also asked to be recognized as a Participating Organization in GEO (Group on Earth Observations), a voluntary partnership of governments 
and international organizations, which is coordinating international efforts to build a Global Observation System of Systems (GEOSS). The aim is to construct a global public infrastructure for Earth observations, which like Internet, will consist of a flexible and distributed network of content providers.

With regard to communications and visibility in relation to the International Year of Planet Earth, which was launched by IUGS to demonstrate the potential role of the Earth sciences for building a safer, healthier and wealthier society, the IUGS has continued supporting this important initiative and has been considering ways in which its results could be built upon beyond 2010. Thus, the IUGS is supporting the OneGeology project, involving the participation of Geological Surveys around the world in the integration of data in standard format within a dynamic web portal. The IUGS is also supporting the interaction this project has with the IUGS CGI, and is looking forward to a closer collaboration on geostandards with other IUGS bodies and the $34^{\text {th }}$ International Geological Congress (Brisbane, 2012). IUGS support of OneGeology is also connected to IUGS interest on possible interactions with Geological Surveys through organizations such as the EuroGeoSurveys and the "Asociación de Servicios de Geología y Minería Iberoamericanos" (ASGMI).

Another important outcome of the IYPE has been the influence it has had on young people and the organization of the First World Young-Earth-Scientists (YES) Congress (25 28 October 2009, Beijing), under the patronage of UNESCO. The IUGS has given its full support to this meeting in the hope that this initiative will result in a permanent world-wide network of young professionals, scientists and politicians, as one of the important legacies of the IYPE.

During 2009 the IUGS dealt with two situations fundamental to its work and visibility. In January 2009, the IUGS was informed by the Norwegian National Committee for Geology that their support to the IUGS Secretariat will be terminated by the end of 2009, an understandable decision after many years of generous support. Thus, the IUGS is now working on the relocation of its Secretariat to another country by the end of 2009. Also as established in a MOU between the China Ministry of Land and Resources and IUGS, China's editorial responsibility for journal Episodes terminated at the end of 2008. In January 2009 the EC of the IUGS expressed its thanks to the Government of China and all the members of the editorial staff for the excellent work done, and at the same time accepted a kind and generous proposal by the Geological Society of India to publish Episodes for the period 2009-2012. Since then a smooth transition of the editorial office from China to India has taken place. Episodes is now published with the same quality standards and is expected to be up-todate by the end of 2009 .

Other important work in connection with policies on communication is underway. This involves the content management system and graphical improvement of the IUGS website, which is now near completion. Last but not least, considering that in the year 2011 the IUGS will celebrate its $50^{\text {th }}$ anniversary, the EC has decided that part of the celebration should be the publication of a book on the "History of the IUGS (1961 - 2011)". A set of guidelines has been established, the help of the Commission on the History of Geological Sciences (INHIGEO) was obtanied and the project is now underway.

On behalf of the EC, I extend my thanks to all those who have helped and are helping on these and other endeavors. As ever the support and collaboration of the whole IUGS constituency is essential to maintain and improve IUGS efficiency in attaining its goals.

\section{Alberto C. Riccardi \\ IUGS President}

